\title{
PARAMETRIC STUDIES OF FAILURE MECHANISMS IN THERMAL BARRIER COATINGS DURING THERMAL CYCLING USING FEM
}

\author{
B. SRIVATHSA* and D.K. DAS \\ Defence Metallurgical Research Laboratory \\ Kanchanbagh, Hyderabad 500 058, INDIA \\ E-mails: srivathsa_boddapati@rediff.com \\ srivathsab@dmrl.drdo.in
}

\begin{abstract}
Thermal barrier coatings (TBCs) are widely used on different hot components of gas turbine engines such as blades and vanes. Although, several mechanisms for the failure of the TBCs have been suggested, it is largely accepted that the durability of these coatings is primarily determined by the residual stresses that are developed during the thermal cycling. In the present study, the residual stress build-up in an electron beam physical vapour deposition (EB-PVD) based TBCs on a coupon during thermal cycling has been studied by varying three parameters such as the cooling rate, TBC thickness and substrate thickness. A two-dimensional thermomechanical generalized plane strain finite element simulations have been performed for thousand cycles. It was observed that these variations change the stress profile significantly and the stress severity factor increases nonlinearly. Overall, the predictions of the model agree with reported experimental results and help in predicting the failure mechanisms.
\end{abstract}

Key words: thermal barrier coatings, residual stress, failure mechanisms, modeling and simulation.

\section{Introduction}

Thermal barrier coatings (TBCs) used on advanced gas turbine engine components increase engine efficiency and performance and thereby prolong the life of these turbine components (Meier et al., 1994; Miller, 1987; Clarke et al., 2003). The schematic representation of a typical TBC system is shown in Fig.1 (Evans et al., 2001). It is now well established that Pt-modified diffusion aluminide (Pt-Al) bond coat in combination with 7\% Yttria Stabilized Zirconia (7 YSZ) ceramic coat provides the best thermal barrier effect for Ni-based superalloy components of gas turbine engine (Meier et al., 1994). The performance of TBCs is affected by several micro-structural factors (Johnson et al., 1998; Schwingel et al., 1998; Alperine et al, 1994), porosity in the ceramic layer (Pekshev et al., 1993) and stress developed in the TBC system, especially during cyclic heating and cooling (thermal cycling) in an engine environment (Scardi et al., 1996; Mcgrann et al., 1998; Qian et al., 1998).

Stresses in a TBC are generated through three events, namely phase transformation, rapid expansion and contractions, and mismatch of thermal expansion coefficients of the substrate and coatings. In the present study of TBC (YSZ) system, stress build-up due to the transformation of zirconia phase, from tetragonal to monoclinic phase and vice versa stress build-up has not been considered. The second contributing component to the overall residual stress is due to a rapid expansion and contraction of the system because of thermal cycling. Typically for a single layer system; mathematically, the magnitude of this stress can be estimated from the following equation

$$
\sigma=\alpha\left(T-T_{r e f}\right) E
$$

\footnotetext{
* To whom correspondence should be addressed
} 
where $\alpha, T, T_{r e f}, E$ are the coefficient of thermal expansion, temperature at any instant and reference of the system and elastic modulus of the material, respectively.

The third component of stresses is the differential thermal contraction (DTC) also known as thermal stress, and is induced by the mismatch in CTE of the substrate and coating. And this component plays a very important role in the overall failure of the ceramic layer. Extensive experimental and modeling work has been carried out to understand the development of these stresses (Evan et al., 2001; Wright et al., 1999: Hsuch et al., 2000; Chun-Hway et al., 2000; Srivathsa et al., 2011; Piotr et al., 2007; Mao et al., 2005; Chen Xiao et al., 2005; Lee et al., 1992). Considering two-dimensional stress-strain analysis, thermal stress at the interface of a two layer system (Chen Xiao et al., 2005) $\sigma_{\mathrm{tb}}$ can be estimated as

$$
\sigma_{t b}=E \Delta \alpha \Delta T(1+v) /\left(1-v^{2}\right)
$$

where $E, \Delta \alpha, \Delta T$ and $v$ are the elastic modulus of coating, CTE mismatch between bond coat and ceramic, temperature difference and Poisson's ratio of the coating, respectively. Both analytical and numerical methods have been adopted to model the development of thermal residual stresses in TBCs considering the presence of surface undulation and plain TGO on the bond coat. Hsueh et al. (2000) and Chun et al. (2000) carried out modeling with convex and concave asperities at bond coat/ceramic interface. They used analytical models where the in-plane cross-section of the TBC system was modeled as three concentric circles, namely bond coat, TGO and ceramic. Residual thermal stresses at the TGO/BC and the TGO/ceramic coat interfaces were then calculated as a function of TGO thickness. Evans et al. (2001) also used an analytical model for computing residual stresses in TBCs. Mao et al. (2011) incorporated creep mechanism in their analytical model to study residual stress build-up in TBCs. Despite these attempts, analytical methods have largely failed to accurately predict the stress states in a complex system such as TBC. Therefore, numerical methods have been increasingly used in recent times. Wright et al. (1999) adopted a numerical model in which they assumed that the material properties vary linearly with temperature. Srivathsa et al. (2011) studied the development of residual stresses using the finite element method considering both planar and undulated TGO. The properties of the constituents of the system are considered as temperature dependent and the effect of undulations on residual stress build-up is discussed. Bednarz (2007) developed a numerical model for simulating thermal stress by taking local and global approach and discussed the effect of thermal shock in stress build-up. Mao et al. (2005) studied the effect of bending moment and curvature on stress variation by considering non-linear elasto-plastic deformation and thermal fatigue. Chen et al. (2005) showed the possibility of crack initiation which also increases the normal stress at the interface of $\mathrm{BC} / \mathrm{TGO}$ in their numerical simulation.

In this study, a two-dimensional (2D) finite element method based numerical model is proposed to study the thermo-mechanical behavior of the system. Simulations are carried-out on a sample subjected to a thermal cycling keeping the cycling furnace conditions in mind. Residual stress developed in TBCs during 1000 thermal cycles is calculated using ANSYS. The main objective of this particular paper is to describe the effect of three critical parameters; namely, the substrate thickness, TBC thickness and rapidity of cooling cycle on the development of residual stresses during thermal cycling and failure mechanisms.

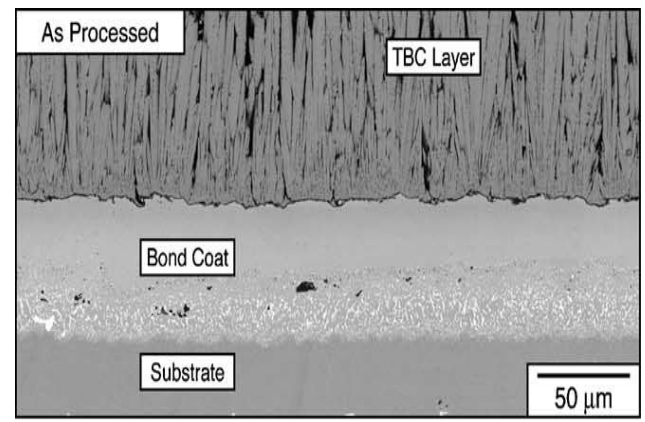

Fig.1. A typical TBC system showing all the constituents (2001). 


\section{Model formulation}

\subsection{Specimen configuration}

The coated specimen considered in this study is schematically shown Fig.2. The specimen (substrate) has a disc shape having a diameter of $30 \mathrm{~mm}$ and thickness of $2 \mathrm{~mm}$. CM-247LC Ni-based superalloy has been considered as the substrate material in this study. The thicknesses of the Pt-Al BC and the 7YSZ ceramic layers are 50 and $100 \mu \mathrm{m}$, respectively. A finite element model was developed for the above TBC system using a coupled field element in ANSYS and to improve the accuracy of the results, the domains were discretized with varying element sizes with the smallest being of the order of $10 \mu \mathrm{m}$. Mesh sensitivity analysis revealed that the above mesh refinement was adequate as the error in the effective strain was less than $0.02 \%$. The above two-dimensional model developed based on conservation principles was used for determining the stresses that develop in the TBC system during cyclic heating and cooling. The heat flux resulting from the thermal load was calculated using Fourier's heat law, which essentially relates the heat flux to the temperature gradient. The temperature gradient causes strains among the constituents of the TBC system because of the differences in their CTEs. The details of the model formulation have been provided in a previous study (Srivathsa et al., 2011).

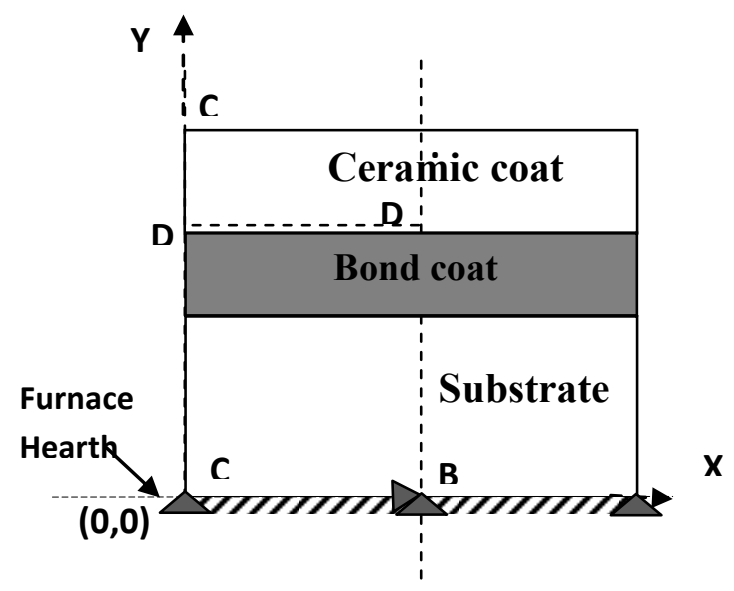

Fig.2. The TBC system used in the present simulation. Filled arrow tips represent the constraints (structural) imposed on the sample.

\subsection{Materials properties}

The three constituents of the TBC are assumed to be homogeneous and isotropic. Thermal and elastic-plastic properties of the substrate and bond coat materials were considered to be temperature dependent, while temperature dependent thermal and elastic properties were considered for 7YSZ coating. Material properties used in the present calculations have been reported elsewhere (Srivathsa et al., 2011; Bednarz et al., 2007). Bilinear isotropic hardening elasto-plastic behaviour has been assumed for the substrate and bond coat materials. Although, the material properties such as the strength, density, modulus etc., of the constituents may vary during thermal cycling (Pan et al., 2003), such variations have been neglected in this study. Similarly, the mechanical properties of all constituents of TBC have also been assumed to remain unaffected during thermal cycling. 


\subsection{Thermal loading}

The TBC coated specimen (Fig.2) was subjected to a thermal cycle consisting of a heating period inside a furnace during which the coated specimen was exposed to the furnace temperature of $1100^{\circ} \mathrm{C}$ for 30 $\min$. Subsequently, the specimen was kept outside the furnace for $30 \mathrm{~min}$ during which cooling of the specimen took place in ambient air. The heating and cooling period of a cycle are schematically shown in Fig.3.

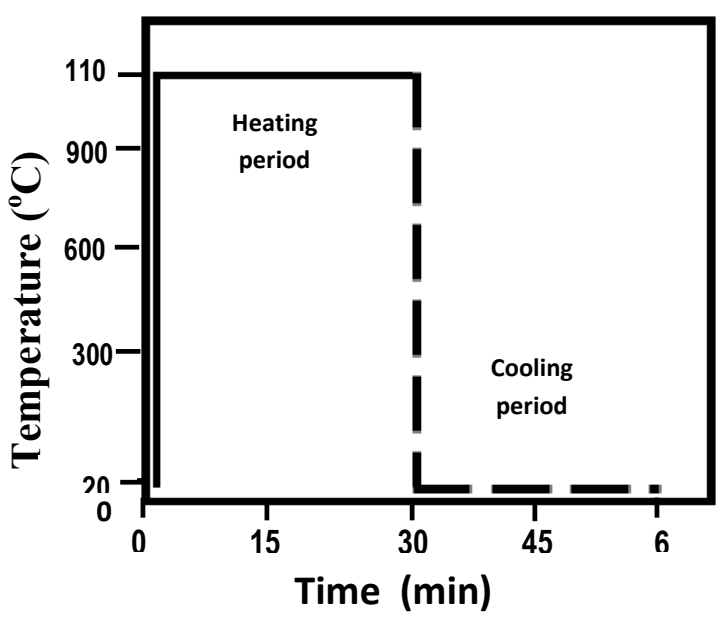

Fig.3. Thermal cycle used for simulation studies.

\subsection{Boundary conditions}

As shown in Fig.2, the sample is placed on the furnace hearth. It has been assumed that the heat transfer between the sample and the surrounding occurs by convection. From heat transfer point of view, while the sides and top surface of the specimen remain completely open to the atmosphere, its bottom surface remains only partially exposed. Therefore, a relatively lower convective heat transfer coefficient has been used for the bottom surface as compared to the other surfaces. Translational motion of the bottom surface of the specimen in the $Y$ direction is not allowed, i.e., the bottom surface which is in contact with the hearth of the furnace, does not move in the $Y$ direction. Further, the mid-point of the bottom surface is constrained in the $x$-direction. Schematically, these thermal and structural boundary conditions are shown in Fig.2.

\subsection{Parametric considerations}

In the present study, three different parameters have been considered in terms of their effect on temperature and stress distribution in the TBC. These parameters are: (a) substrate thickness, (b) ceramic (7YSZ) layer thickness, and (c) rapidity of cooling during the cooling period. Rapidity of cooling has been varied by altering the convection coefficient. In the present study, one parameter at a time has been changed while assessing the effects of these parameters. All combinations of these parameters for which computations were made are listed in Tab.1 along with their values. Structural boundary conditions have been kept same in all the cases. 
Table 1. Various combinations of parameters considered for simulations in this study. The BC thickness has been kept constant at $50 \mu \mathrm{m}$ in all the cases.

\begin{tabular}{|c|c|c|c|c|c|}
\hline Condition & $\begin{array}{c}\text { Substrate } \\
\text { thickness } \\
(\mathrm{mm})\end{array}$ & $\begin{array}{l}\text { Ceramic layer } \\
\text { thickness }(\mu m)\end{array}$ & $\begin{array}{c}\text { Heating } \\
\text { period } \\
1100^{\circ} \mathrm{C} \\
\end{array}$ & $\begin{array}{l}\text { Cooling } \\
\text { period }\end{array}$ & $\begin{array}{l}\text { Type of air cooling } \\
\text { used ( } \eta \text { in } W / m^{2} \cdot K^{-1} \text { ) }\end{array}$ \\
\hline \multicolumn{6}{|c|}{ Variation of rapidity in cooling } \\
\hline 1 & \multirow[t]{3}{*}{2} & \multirow[t]{3}{*}{100} & \multirow{3}{*}{30 min. } & \multirow[t]{3}{*}{$30 \mathrm{~min}}$. & Natural cooling $(\eta=5)$ \\
\hline 2 & & & & & Natural cooling $(\eta=10)$ \\
\hline 3 & & & & & Natural cooling $(\eta=25)$ \\
\hline \multicolumn{6}{|c|}{ Variation of 7YSZ thickness } \\
\hline 4 & \multirow[t]{4}{*}{2} & 50 & \multirow[t]{4}{*}{$30 \min }$. & \multirow[t]{4}{*}{$30 \mathrm{~min}$} & \multirow{2}{*}{ Natural cooling $(\eta=5)$} \\
\hline 5 & & 300 & & & \\
\hline $6^{\prime}$ & & 50 & & & \multirow{2}{*}{ Natural cooling $(\eta=25)$} \\
\hline $6 "$ & & 300 & & & \\
\hline \multicolumn{6}{|c|}{ Variation of substrate thickness } \\
\hline 7 & 0.5 & \multirow[t]{2}{*}{100} & \multirow[t]{2}{*}{$30 \mathrm{~min}$} & \multirow[t]{2}{*}{30 min. } & \multirow[t]{2}{*}{ Natural cooling $(\eta=5)$} \\
\hline 8 & 5 & & & & \\
\hline
\end{tabular}

\subsection{Simulation details}

An appropriate constitutive formulation is required to describe the behavior of the TBC system during thermal cycling, in particular the coupling between the local expansion associated with thermal fields and generation of local stresses. The formulation accounts for the formation of oxide layer by oxidation with Al-rich bond coat and incorporates the effect of local volumetric expansion of newly formed oxide and generation of inelastic volumetric strain and residual stresses. It relies on the level of oxygen concentration (which is assumed to be available abundantly at bond coat/ceramic coat interface) available at the interface.

The model is based on the conservation principles and is used for determining the stresses that develop in the system due to thermal load imposed during heating and cooling cycle. The heat flux resulting from the thermal load is calculated using the Fourier's heat law, which essentially relates the heat flux to the temperature gradient. The temperature gradient causes differing thermal strains in various constituents of the TBC system. The resulting stresses are calculated using the structural-thermal coupling approach through thermo-elastic stiffness matrix. The equations used in this model for transient heat transfer in solids is as follows

$$
\rho C_{p} \frac{\partial T}{\partial t}+\nabla \cdot(-K \nabla T)=Q
$$

where $T$ is the absolute temperature $(K), \rho$ is the density $\left(\mathrm{kg} / \mathrm{m}^{3}\right) C_{p}$ is the specific heat capacity at constant pressure $(J /(\mathrm{kg} \cdot \mathrm{K})), k$ is the thermal conductivity $(\mathrm{W} /(\mathrm{m} \cdot \mathrm{K}))$ and $Q$ is the heat source $\left(\mathrm{W} / \mathrm{m}^{3}\right)$. In structural mechanics, the equations of equilibrium describe how stress can vary within a body. These equations are obtained from balancing external forces with internal resistance of the material. In plane strain condition, it is assumed that the displacements are permitted only in two directions, and they do not vary as a function of the third direction; i.e., displacements in the third direction are zero. Therefore the equilibrium equations corresponding to the plane strain condition are given by

$$
\frac{\partial \sigma_{x}}{\partial x}+\frac{\partial \tau_{x y}}{\partial y}+F_{x}=0
$$




$$
\frac{\partial \tau_{x y}}{\partial x}+\frac{\partial \sigma_{y}}{\partial y}+F_{y}=0
$$

where $\sigma_{x}, \sigma_{y}$ are stresses in the $x$ and $y$ directions, respectively and $\tau_{x y}$ is shear stress. The elastic response of the body cannot be obtained from the above equilibrium equations; for this compatibility conditions are used and generally these are expressed in terms of strain (better for 2-D problems) or displacement (better for 3-D problems). For the plane strain problem the compatibility equation used is given below

$$
\frac{\partial^{2} \varepsilon_{x}}{\partial y^{2}}+\frac{\partial^{2} \varepsilon_{y}}{\partial x^{2}}=2 \frac{\partial^{2} \tau_{x y}}{\partial x \partial y}
$$

where $\varepsilon_{x}, \varepsilon_{y}$ are strains in the $x$ and $y$ directions, respectively and $\varepsilon_{x z}$ is shear strain. The constitutive equation used for elastic-plastic response of the material is the power law given as

$$
\sigma=K \varepsilon^{n}
$$

where $\sigma$ is the stress, $K$ is the strength coefficient and $n$ is the strain hardening exponent. Two-dimensional plane strain finite element simulations have been performed using ANSYS 13.0. A transient thermomechanical coupled analysis has been employed for carrying-out the simulation with Von-Mises yield criterion. Bilinear isotropic hardening elasto-plastic behavior has been assumed for the substrate and bond coat materials, whereas the linear elastic model have been considered for TGO and 7 YSZ ceramic coating. A frontal solver has been used with Newton-Raphson iterative method. High performance computing features on a single machine with distributed memory option have been used to reduce the computational time. This approach helps in increasing load convergence in both force and displacement. In this approach, the tolerance in force for achieving a convergence in the solution has been 0.0001 under $L_{2}$ Norm. The ANSYS/CAE program has been used for pre and post processing of the data. The results have been captured in multiple sub-steps at critical locations for a better understanding of the process.

\section{Results and discussions}

Residual stresses computed from the present finite element study are mainly due to differential thermal contraction and also to rapid expansion and contraction during the thermal cycling. The specimen has been subjected to 1000 thermal cycles and stress distributions are calculated for the entire TBC system. Three stress components namely: (i) radial stress ( $\sigma_{x}$ or in-plane stress) component that refers to the stress parallel to the interface; (ii) normal stress ( $\sigma_{y}$ or out-of-plane) component corresponding to stress profile through the thickness of the coatings or perpendicular to the interface; and (iii) shear stress $\left(\sigma_{x y}\right)$ in the $x y$ plane have been considered as these are mainly responsible for TBC failure.

It can be expected that the rate of change of stress, i.e., stress change (build-up or relaxation) at a given location and any instance during cooling cycling is going to be a critical factor from the stand point of TBC failure. A higher rate of change of stress would likely cause a faster TBC failure. To examine this aspect, the maximum value in the plot $d \sigma_{x} / d t$ vs time plots, i.e., $\left(d \sigma_{x} / d t\right)_{\max }$, has been used to indicate the severity in stress change at the interfaces. The above factor, i.e., $\left(d \sigma_{x} / d t\right)_{\max }$ has been referred as stress severity factor (SSF) in this paper.

\subsection{Verification of the model}

The accuracy of the finite element model was verified by comparing the computational result of residual stress in a two-layer system, considering the bond coat and ceramic coat, with the analytical solution 
of stress $\left(\sigma_{x}\right)$ at the coating surface using Eq.(1.2). A comparison of residual stress at the $7 \mathrm{YSZ} / \mathrm{BC}$ interface is shown in Fig.4. And it can be seen that the calculated residual stress $(-255 \mathrm{MPa})$ at the interface of the bond coat/ceramic coat having $100 \mu \mathrm{m}$ coating thickness agrees well with the analytical value obtained from Eq.(1.2). As expected, an increase in the coating thickness, e.g. $300 \mu m$ coating would lead to a greater deviation of FE result from the analytical solution. As the validity of the FE model has been verified, the analyses were extended to include the substrate taking it as a gradient TBC system.

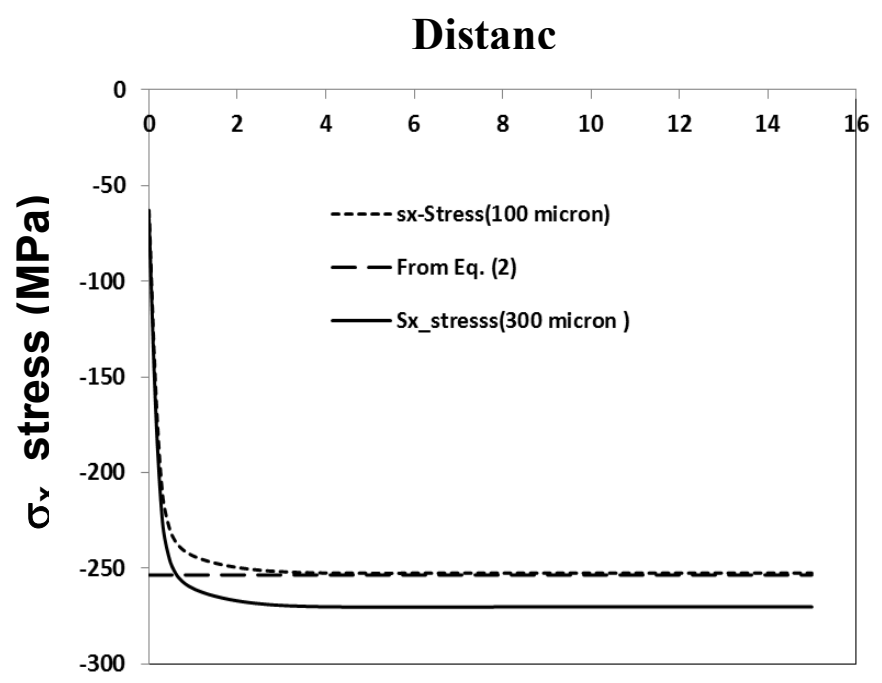

Fig.4. Stress distribution at the substrate/BC interface in the axial direction during hold time plotted as a function of radial distance from the edge of the specimen to the center of the specimen.

\subsection{Typical temperature and stress distribution during a thermal cycle}

As previously mentioned, simulations were carried-out on the $2 \mathrm{D}$ specimen shown in Fig.2. for the conditions mentioned in Tab.1. The temperature change at the midpoint of 7YSZ/BC interface (Point A Fig.2.) with time during the first thermal cycle is as shown in Fig.5. The temperature at this point attains the furnace temperature of $1100{ }^{\circ} \mathrm{C}$ in about $6 \mathrm{~min}$. after which it remains constant at this value for the remaining duration of heating period. During the cooling period, the temperature drops under natural cooling quickly from $1100{ }^{\circ} \mathrm{C}$ to $120{ }^{\circ} \mathrm{C}$ in about $10 \mathrm{~min}$. Subsequently, the temperature drops fairly slowly as evident from Fig.5. A similar trend is observed during subsequent thermal cycles (up to 1000 cycles). The stress $\left(\sigma_{x}\right)$ build-up at point A corresponding to the above temperature change has also been plotted in Fig.5. It is evident from this figure that the stress at the interface remains compressive and reaches a maximum of $255 \mathrm{MPa}$ during the heating period and these compressive stresses were released during the cooling cycle. At the end of the cooling cycle, the stress becomes near zero. Stress $\left(\sigma_{x}\right)$ distribution through the center across the thickness of the specimen (along the line B-B in Fig.2.) has been plotted as shown in Fig.6. From this figure it is clear that during the heating and cooling cycle, interfaces are the only stress concentration regions across the thickness of the specimen. Compressive stresses (255 $\mathrm{MPa}$ ) developed at the interface are relaxed to $120 \mathrm{MPa}$ during the cooling cycle. Also, stress gradients are very high at $7 \mathrm{YSZ} /$ bond coat interface during the heating and cooling cycle. And a clear stress reversal can be noticed across the interfaces. While the substrate and top coat remain under tension during thermal cycle, the bond coat remains in compression.

In Fig.7 stresses $\left(\sigma_{y}\right)$ are plotted along the line B-B (Fig.2.) of the specimen during the first thermal cycle. It can be noticed that during the heating cycle, the specimen is subjected to tensile stress and the maximum stress is noticed at the 7YSZ/bond coat interface with high stress gradients. While experimentally measured the maximum stress at the $7 \mathrm{YSZ} / \mathrm{BC}$ interface is around $70 \mathrm{MPa}$ (Pan et al., 2003) which is in 
good agreement with the present FEA results; although, simulated stresses are slightly lower than the measured values. This could be attributed to the effect of interface roughness of specimen, FEA performed in this study assumed flat interfaces between dissimilar materials. On the contrary, it has been shown that surface roughness generates higher stresses $\left(\sigma_{y}\right)$ (Shillington et al., 1999). The surface of the top coat retained a very small tensile stress $(0.0052 \mathrm{MPa})$ at the end of the first thermal cycle. With thermal cycling this tensile stress has slowly become compressive and the effect of this will be discussed later. Further, stress $\left(\sigma_{y}\right)$ distribution along the line C-C (Fig.2.) of the specimen has been plotted as shown in Fig.8. During the heating cycle stresses at the free edge are practically zero, because expansions during heating were not restrained. Although, it is true even during the cooling cycle, but due to CTE mismatch, stresses build-up significantly in the TBC system. While compressive stresses are observed within the substrate, the maximum tensile stresses have been noticed at BC/7YSZ interface.

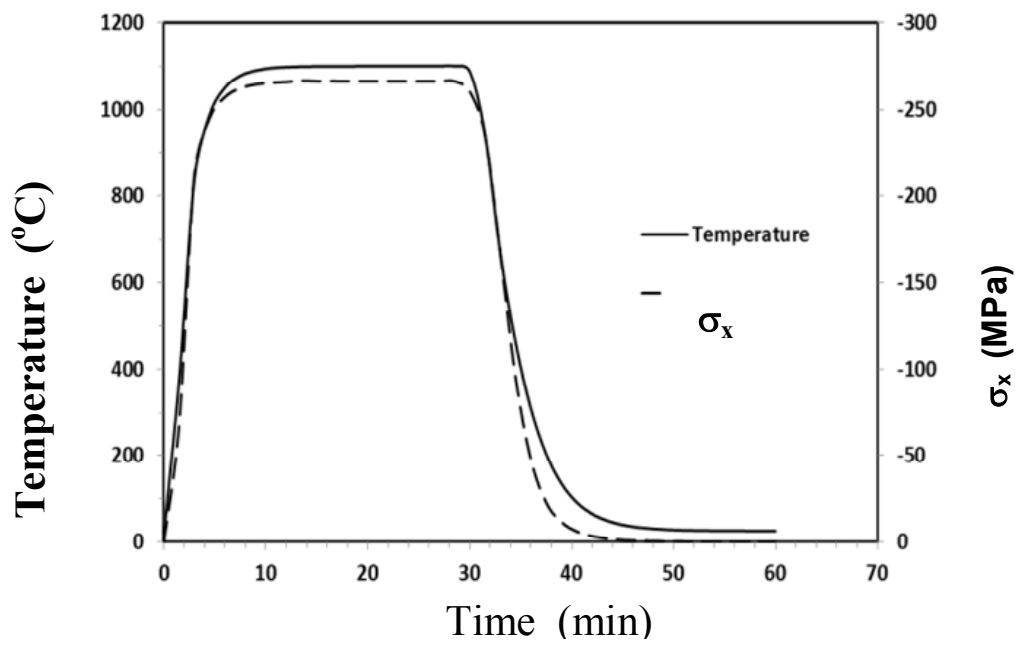

Fig.5. Temperature and stress $\left(\sigma_{x}\right)$ distribution at point A (Fig.2) during the first thermal cycling.

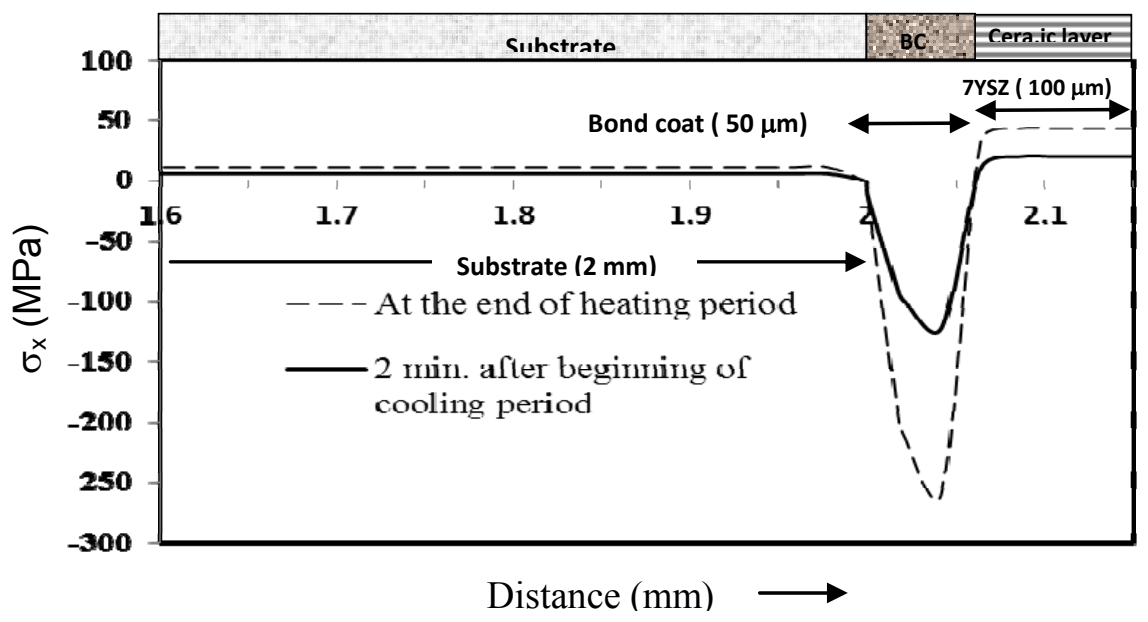

Fig.6. Stress $\left(\sigma_{x}\right)$ distribution along the line B-B shown in Fig.2. 


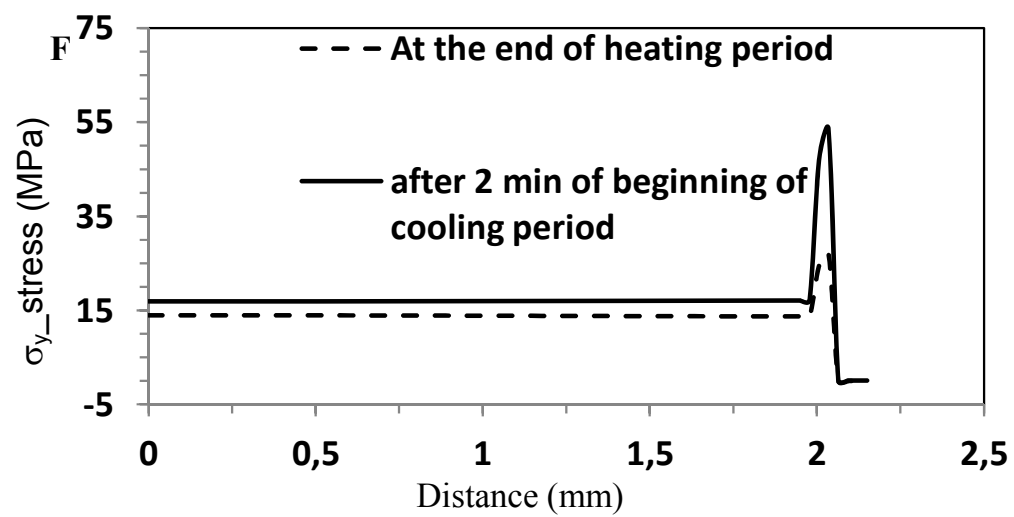

Fig.7. Stress $\left(\sigma_{y}\right)$ distribution along the line B-B (Fig.2.).

Also, the stress gradients are very high at the BC/7YSZ interface. These gradients may lead to openingup the top coat from the edge of the specimen. This opened edge of coating or delamination of coating may be further assisted by stress $\left(\sigma_{y}\right)$ distribution from the edge to the center along the 7YSZ/bond coat interface (line D-D in Fig.2). This stress $\left(\sigma_{y}\right)$ distribution is as shown in Fig.9. A maximum stress of $230 \mathrm{MPa}$ was found near the free edge of the specimen and this value is decreased with distance from edge to the centre. Also, it has been observed that the shear stress showed a considerable stress concentration at the BC/7YSZ interface near the free edge. Hence, this tensile stress $\left(\sigma_{y}\right)$ may cause spallation of the coating, initiated at the free edge, which propagates radially towards the center region of the specimen causing a progressive delamination (Evans et al., 1999; Karlsson et al., 2002) with thermal cycling. The magnitudes of the stress at the 7 YSZ/BC interface and stress states during the thermal cycle are in good agreement with the earlier reported/measured values (Evans et al., 1999; Karlsson et al., 2002). Further, the results of these simulation studies have been analyzed by considering only $\sigma_{x}$ stresses as these are more critical from failure point of view.

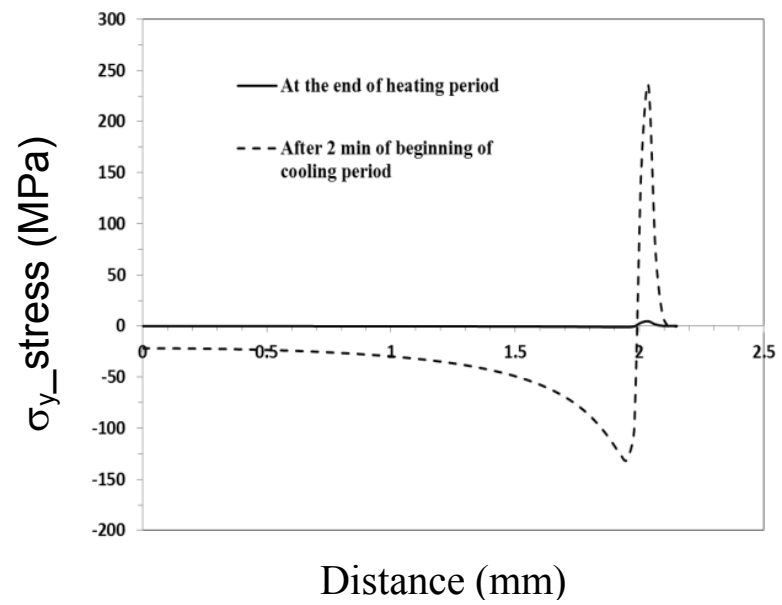

Fig.8. Stress $\left(\sigma_{y}\right)$ distribution along the line C-C (Fig.2).

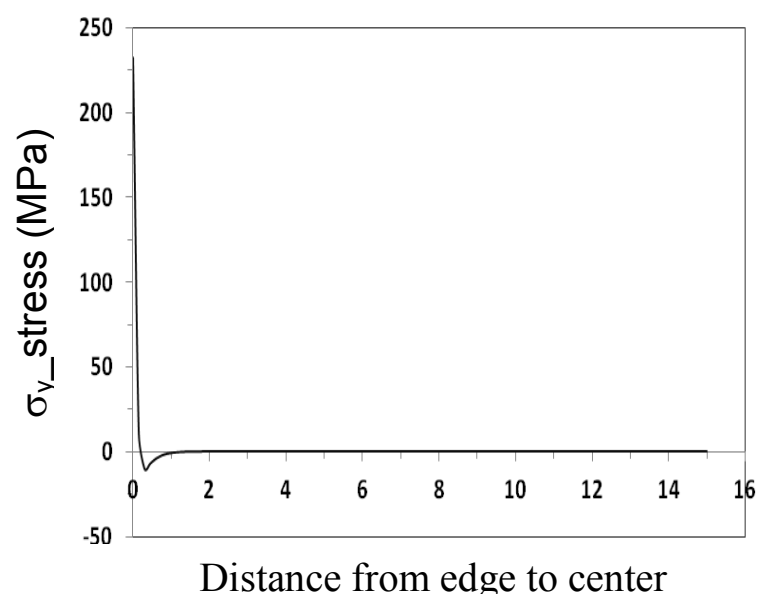

Fig.9. Stress $\left(\sigma_{y}\right)$ distribution along the line D-D (Fig.2).

\subsection{The effect of cooling rate}

In actual gas turbine environments, TBC components undergo cooling with various rapidity during thermal cycling. Rapidity in cooling (or the rate of heat extraction during the cooling period) can affect the life of TBCs. In fact, a reduced life of TBCs under forced cooling as compared to that under natural cooling has been reported (Karlsson et al., 2002; Karlsson et al., 2002; Karlsson et al., 2002; Helminaik, 1998; Stephan, 1985; Karlsson et al., 2001). As mentioned previously, the effect of rapidity in the cooling during cooling period has been examined by considering three different convective heat transfer coefficients during 
the cooling period and the heat transfer coefficient during the heating period has been kept constant in all the three above conditions. The variation of temperature and stress with time at location A (Fig.2.) during the first thermal cycle is shown in Figs 10a and b respectively. As expected, the temperature variation in all the three constituents (7YSZ, BC and substrate) is identical during the heating period as the same convective coefficient has been considered during this period. During the cooling period, however, the effect of rapidity in cooling is clearly visible, as shown in Fig.10a. The rate of temperature drop for a higher coefficient is much higher than that for a lower one. A similar trend is also evident in terms of stress variation with time as shown in Fig.10b. The effect of rapidity in cooling becomes more evident in the plot: rate of stress change $\left(d \sigma_{x} / d t\right)$ vs. time, as shown in Fig. 11. The value of stress change $\left(d \sigma_{x} / d t\right)_{\max }$ or SSF for $\eta=25 W \cdot m^{-2} \cdot K^{-1}$ is around $90 \mathrm{MPa} \cdot \mathrm{s}^{-1}$ which is nearly twice the value of $45 \mathrm{MPa} \cdot \mathrm{s}^{-1}$ corresponding to $\eta=5 \mathrm{~W} \cdot \mathrm{m}^{-2} \cdot \mathrm{K}^{-1}$. Thus, it is apparent that the severity of stress change at the BC/7YSZ interface during the cooling period of any given cycle increases significantly by increasing the rapidity in cooling, i.e., increasing the value of $\eta$. Due to this, the chances of the $7 \mathrm{YSZ} / \mathrm{BC}$ interface failure are high. Because more heat will be dissipated to the air with a higher convection coefficient, less heat will be transferred by conduction to the adjacent layer(s). Therefore, the underlying substrate would be at a lower temperature, resulting in lower induced thermal stress component. These results are in good agreement with those given by Bialas (2008). If no temperature gradient is considered during the cooling, the stress would remain in compression (Zhang Yue et al., 2001). Therefore, the cooling rate rather than the temperature difference of the thermal cycle is crucial for crack formation at the interface (Teixeira et al., 1992; Zhang Yue et al., 2001; Zhu et al., 1999).
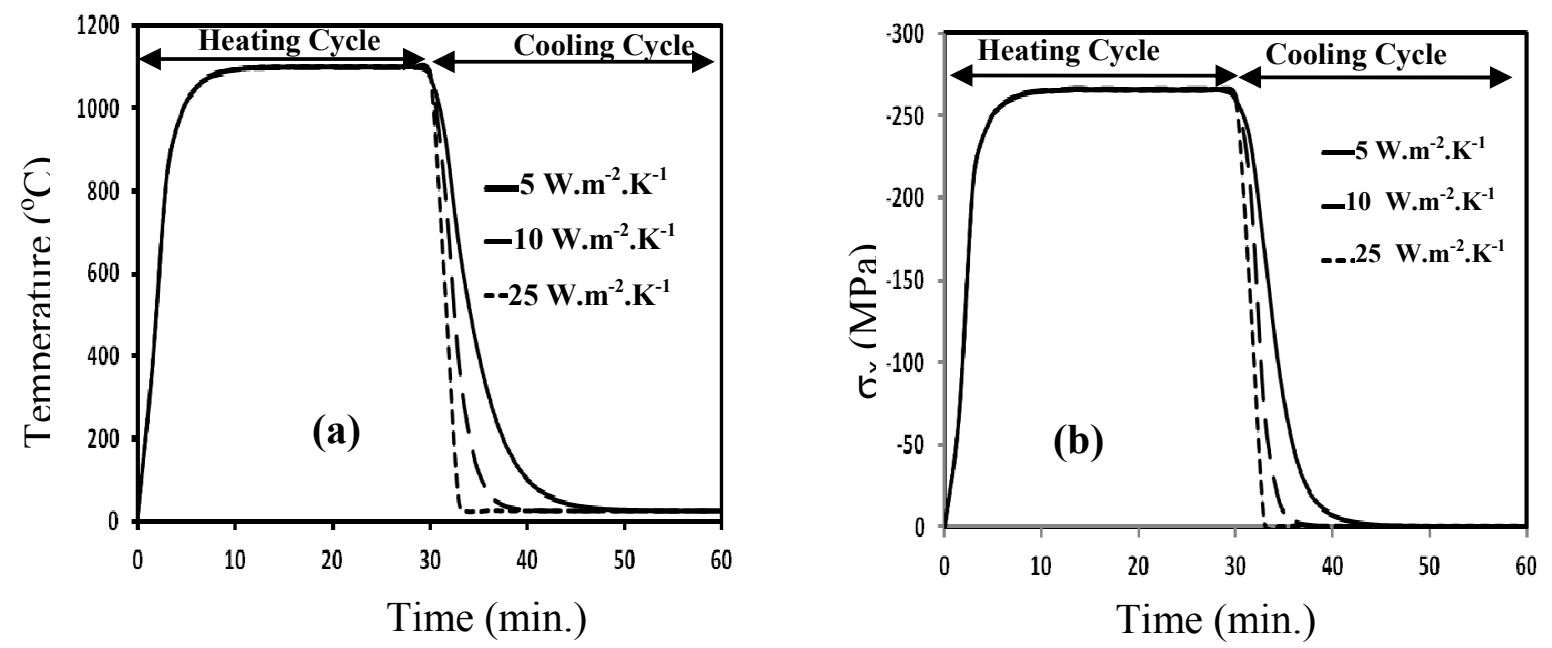

Fig.10. The effect of rapidity in cooling at point A (Fig.2) in terms of (a) temperature and (b) stress.

\subsection{The effect of thermal barrier coating thickness}

One way to have a higher operating temperature in the gas turbine engine would be to use a thicker 7YSZ ceramic coat. This would produce a higher temperature gradient across the ceramic layer and, therefore, keep the metallic bond coated substrate at a comparatively lower temperature. Simulations have been carried out using three different ceramic layer thicknesses to examine the effect of thickness on the stress developed at the $7 \mathrm{YSZ} / \mathrm{BC}$ interface. A stress analysis has been carried out with the 7YSZ layer of thickness of 50,100 and $300 \mu \mathrm{m}$. The other parameters used for simulation were kept same as listed under Conditions 1, 10 and 11 in Tab.1. The variations of stress at point A (Fig.2.) with time during the first thermal cycle are plotted in Fig.12. for the above three ceramic layer thicknesses. It is evident that the variation in stress, at point A remains virtually the same during both heating and cooling periods of all three ceramic layer thicknesses. In other words, the ceramic layer thickness has no appreciable effect on the stress $\left(\sigma_{x}\right)$ change at the $7 \mathrm{YSZ} / \mathrm{BC}$ interface during the first cycle. This is also evident in terms of the variation in $d \sigma_{x} / d t$ with time during the cooling period as shown in Fig.13. It is important to point out here that the bottom surface of the coated specimen in the present configuration (Fig.2) is resting on the furnace base and 
is not directly exposed to the environment. Therefore, a lower convection coefficient has been considered for this surface. In actual application of TBC coated hollow components, however, this surface will be internally cooled by passing air. In such case, the convection coefficient for this surface would be much higher than the value as considered in this study.
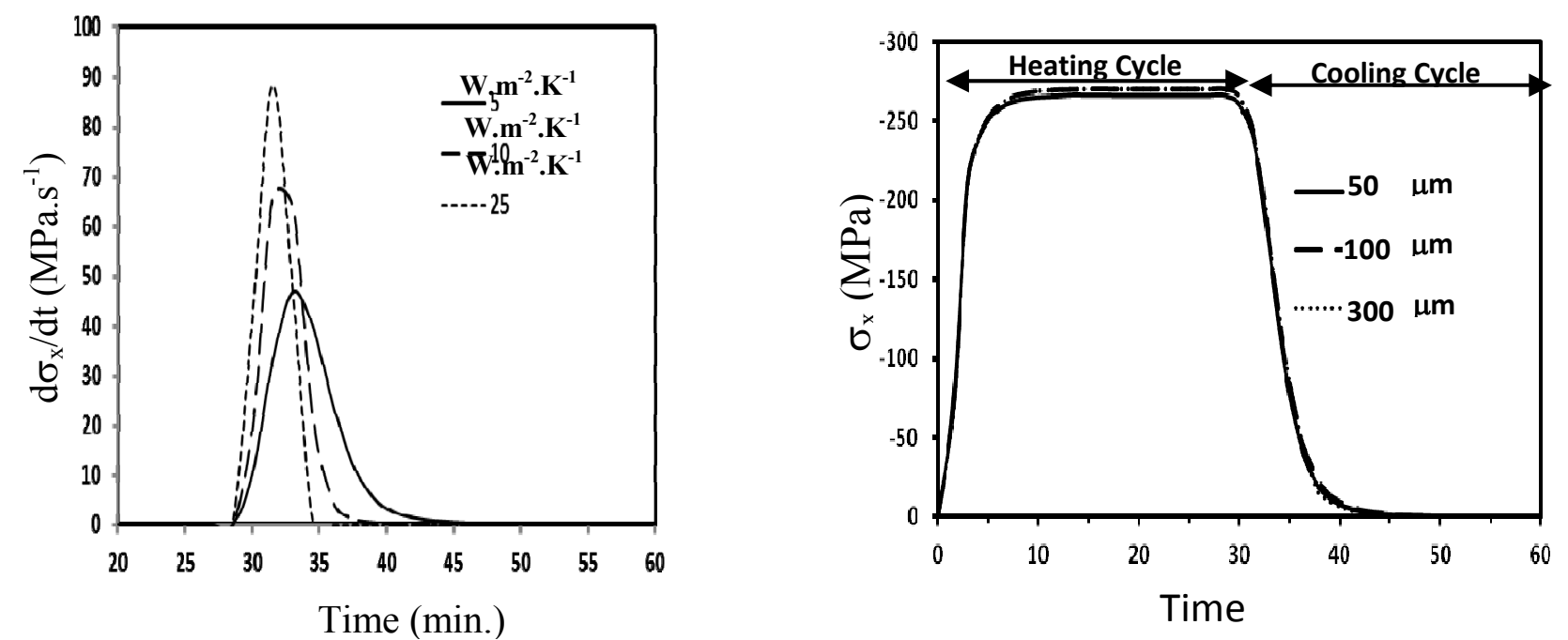

Fig.11. Stress gradients at 7YSZ/BC interface. Fig.12. The effect of 7YSZ layer thickness at point A (Fig.2) during first thermal cycle on $\sigma_{x}$ stress.

To examine this aspect, a hypothetical situation was considered where the convection coefficient for the bottom surface of the sample is much higher. The other conditions are kept constant as mentioned before (see conditions 6' and 6" in Tab.1). A comparison of $\sigma_{x}$ and temperature for this hypothetical situation was carried out for ceramic layer thicknesses of 50 and $300 \mu \mathrm{m}$. Figure 14 shows the $\left(d \sigma_{x} / d t\right)$ vs. time plot for the first cycle for the convection coefficient of $25 \mathrm{~W} \cdot \mathrm{m}^{-2} \cdot \mathrm{K}^{-1}$ for two ceramic thicknesses, namely 50 and $300 \mu \mathrm{m}$. It is clear that $\left(d \sigma_{x} / d t\right)_{\max }$ or SSF for the higher ceramic thickness $(300 \mu \mathrm{m})$ at $52 \mathrm{MPa} \cdot \mathrm{s}^{-1}$ is nearly $20 \%$ lower than the value of $65 \mathrm{MPa}_{\mathrm{s}} \mathrm{s}^{-1}$ obtained for the lower thickness of the ceramic coating $(50 \mu \mathrm{m})$. From the above results, it can be expected that in the actual application, the ceramic layer thickness would have a much more significant effect as compared to that observed in this study.

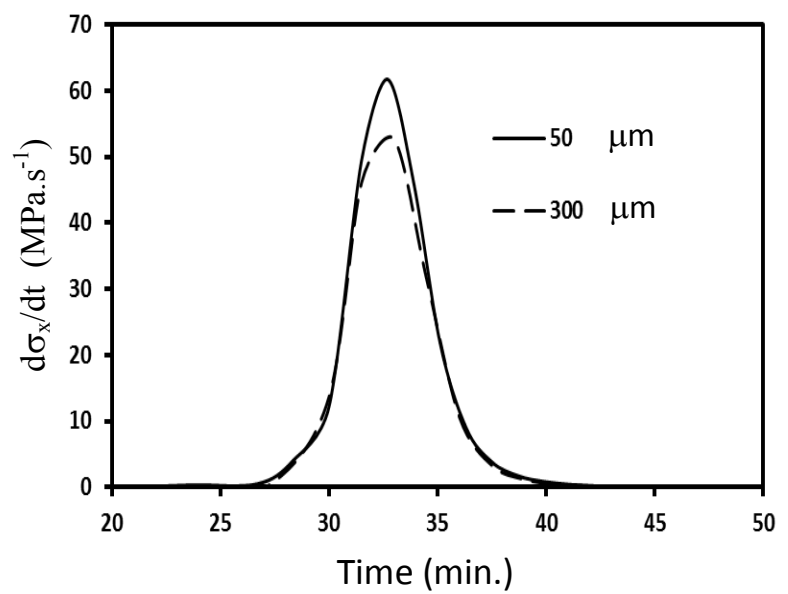

Fig.13. The effect of 7YSZ layer thickness on rate of stress change at point A during the first thermal cycle.

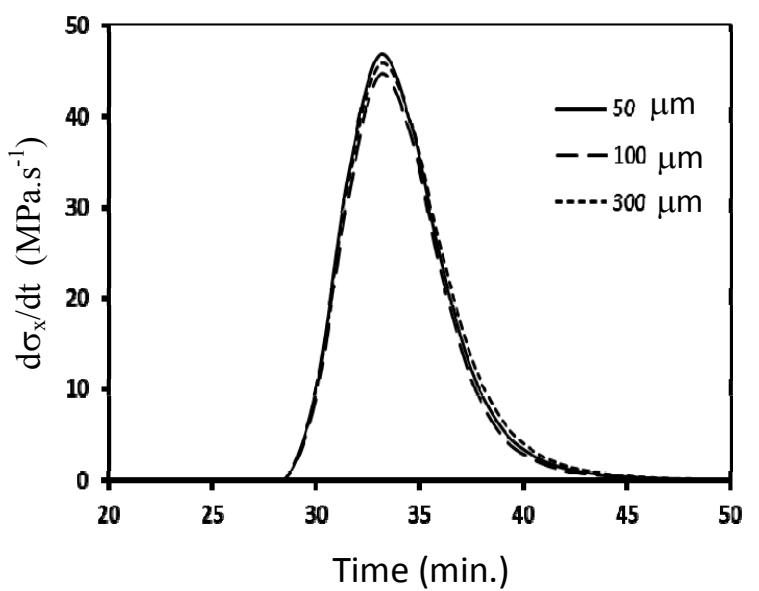

Fig.14. The effect of coating thickness on $d \sigma_{x} / d t$ when a higher $\eta\left(=25 \mathrm{~W} \cdot \mathrm{m}^{-2} \cdot \mathrm{K}^{-1}\right)$ at the bottom surface of the coated sample is used. 
However, the effect of TBC thickness can be seen across the thickness of the specimen as shown in Fig.15. From this figure, it is clear that an increase in coating thickness resulted in reducing stresses in the substrate but in increases the tensile stresses of the top coat, whereas, the bond coat and substrate/BC interface has become more compressive. This is because of the greater thermal gradients, which lead to higher thermal stresses that occur within the top coat. In addition, the increased thickness of the coating will increase the stored elastic strain energy which increases the energy release rate for crack propagation. An increased top coat thickness also increases the shear stresses near the free edge, because of this increase in coating thickness the life of these coatings may decrease. Therefore, one can notice that there is an optimum topcoat thickness between extremely thick and thin top coatings. In addition, these layers are desired to be thin and low density to limit the centrifugal load on rotating engine components and have good thermal and mechanical compatibility.

For these reasons, thick topcoats fail because of spalling, cracking, and chipping within the topcoat layer, whereas thinner coatings are less susceptible to these types of failures and are affected more so by thermal expansion mismatch between the various layers and by oxide formation at the $7 \mathrm{YSZ} / \mathrm{BC}$ interface.

\subsection{The effect of substrate thickness}

Turbine components such as blades and vanes have varying section thickness with minimum thickness as low as $0.5 \mathrm{~mm}$ and maximum thickness up to $5 \mathrm{~mm}$. Such variation in substrate thickness can potentially cause significant stress variations among various locations of the component during thermal cycling (Hutchinson, 2001; Faulhaber et al., 2006; Karlsson et al., 2002). The effect of substrate thickness on stress build-up in TBCs has been simulated by considering substrates of three different thicknesses, namely $0.5,2$ and $5 \mathrm{~mm}$. The other parameters used for simulation have been kept constant, as mentioned under conditions 1, 12 and 13 in Tab.1. From Fig.16, it is apparent that the temperature and the corresponding stress distribution for different substrate thicknesses are very different. For example, as the substrate thickness decreases from $5 \mathrm{~mm}$ to $0.5 \mathrm{~mm}$, the rise in temperature at the interface (at point A in Fig.2) during the heating period and fall in temperature during cooling period occur at a much faster rate. The temperature at the $\mathrm{BC} / 7 \mathrm{YSZ}$ interface drops from $1100^{\circ} \mathrm{C}$ at the beginning of the cooling period to close to RT in $3 \mathrm{~min}$ for the substrate thickness of $0.5 \mathrm{~mm}$. The corresponding duration over which such a temperature drop occurs in case of a $5 \mathrm{~mm}$ thick substrate is much higher at $30 \mathrm{~min}$. This differential rate of cooling caused by the variation in the thickness of the substrate affects the rate of stress change at the $\mathrm{BC} / 7 \mathrm{YSZ}$ interface during the cooling period, as evident from Fig. 17. From the $d \sigma_{x} / d t$ vs. time plot for the first thermal cycle for the above three substrate thicknesses it is apparent that the $\left(d \sigma_{x} / d t\right)_{\max }$ or SSF corresponding to $0.5 \mathrm{~mm}$ thick substrate at $75 \mathrm{MPa}^{-1}$ is nearly 4 times higher than that for a $5 \mathrm{~mm}$ thick substrate. The SSF for a $2 \mathrm{~mm}$ thick substrate is about 2 times lower than that for a $0.5 \mathrm{~mm}$ thick substrate. Thus, it is clear that the variation in the thickness of the substrate (for a given bond coat and 7 YSZ thicknesses) would have a major effect on the life of the TBC. This aspect is important in the context of turbine engine components (blades and vanes) where TBCs on the thinner sections of the component would be more vulnerable to failure. 


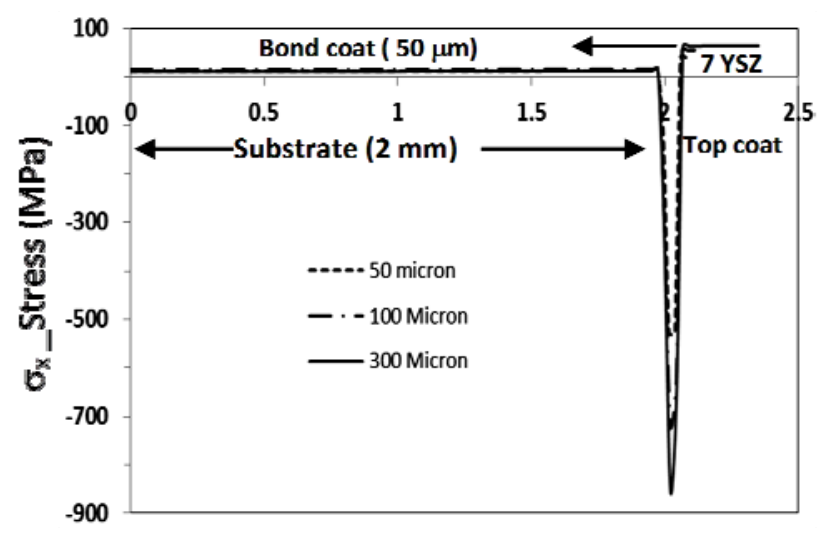

Fig.15. The effect of TBC thickness on stress distribution along the line B-B (Fig.2.).

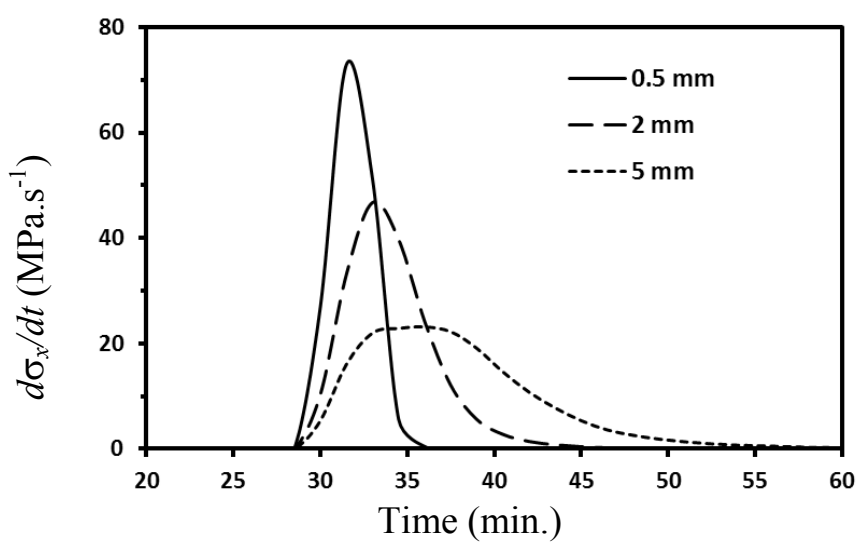

Fig.17. The effect of substrate thickness on stress severity factor.

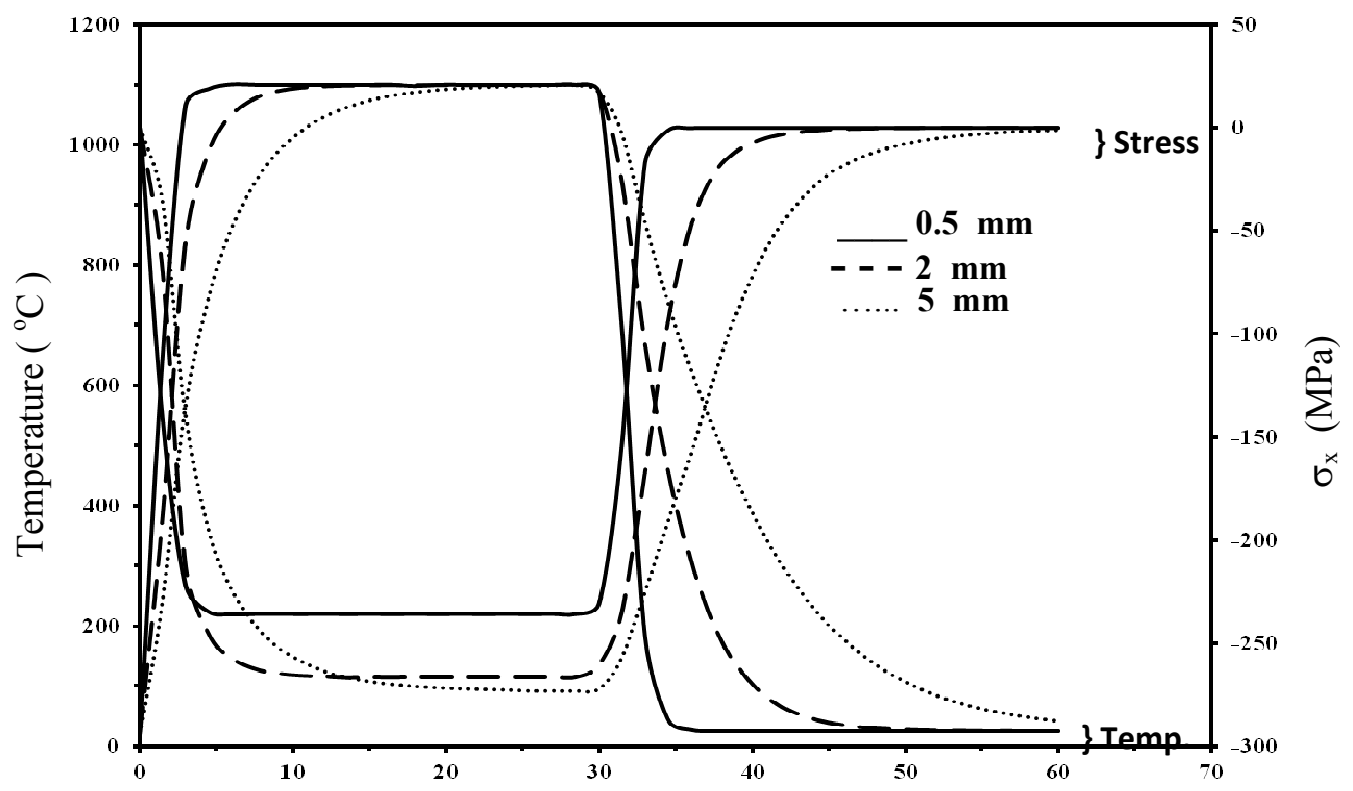

Fig.16. The effect of substrate thickness on temperature and stress distribution.

\subsection{Stress variation over 1000 thermal cycles}

The results pertaining to the effect of various factors such as the cooling rate, substrate thickness etc. on the stress change at the $\mathrm{BC} /$ ceramic layer interface, as presented in the preceding sections, have been obtained in the first thermal cycle. However, coated components in the actual use undergo several thermal cycles before the ceramic layer fails. To examine the stress build-up in such a situation, simulations were carried-out up to 1000 thermal cycles, as previously mentioned. Figure 18 shows the change of SSF with the number of cycles for various rapidities of cooling (as expressed in terms of convection coefficients). It is clear from this figure that SSF for any given $\eta$ does not vary appreciably with the number of cycles over the 1000 cycle duration. For example, SSF for $\eta=25 \mathrm{~W} \cdot \mathrm{m}^{-2} \cdot \mathrm{K}^{-1}$ remains virtually constant at about $90 \mathrm{MPa} \cdot \mathrm{s}^{-1}$ over 1000 cycles. The same for $\eta=5 \mathrm{~W} \cdot \mathrm{m}^{-2} \cdot \mathrm{K}^{-1}$ increases only slightly from about $47 \mathrm{MPa} \cdot \mathrm{s}^{-1}$ for the first cycle to about $55 \mathrm{MPa}^{-1} \mathrm{~s}^{-1}$ after 1000 cycles. This trend of SSF remaining virtually constant over the 1000 cycles is also found in case of other factors, as typically shown in terms of the effect of substrate thickness in Fig.19. It is evident from these results that although the factors considered, namely, the cooling rate, 
substrate thickness, ceramic layer thickness and heating/cooling durations, may significantly affect the rate of stress change at the 7YSZ/BC interface in all individual thermal cycles; there is no cumulative effect of these factors over multiple thermal cycles.

In the present simulation study, the effect of temperature changes during thermal cycling on the change in stresses in a typical TBC system has been considered. It is important to point out that many factors other than temperature variation also cause changes in stresses in the TBC. Prominent among these factors are the TGO growth, rumpling in the bond coat, microstructural changes in the bond coat and ceramic coating. Even sintering of the columns in the ceramic layer over long periods of high temperature exposure (Sujanto Widjaja et al., 2003; Karlsson et al., 2002; Limarga et al., 2002; He et al., 2000) and creep deformation (Hutchinson, 2001) can also lead to changes in stresses in the TBC. The effect of rumpling has been already discussed in our earlier paper (Srivathsa et al., 2011) and the effect of dynamic growth of TGO is currently under study. However, the results do provide a quantitative understanding of the effect of thermal stresses develop in TBCs during thermal cycling. For example, a five-fold increase in the value of the convective coefficient (from 5 to $25 \mathrm{~W} \cdot \mathrm{m}^{-2} \cdot \mathrm{K}^{-1}$ ) increases the SSF value by about two times (Fig.7). A ten-fold of increase in the substrate thickness (from $0.5 \mathrm{~mm}$ to $5 \mathrm{~mm}$ ) on the other hand decreases the SSF by a factor of about 4.5 (Fig.12).

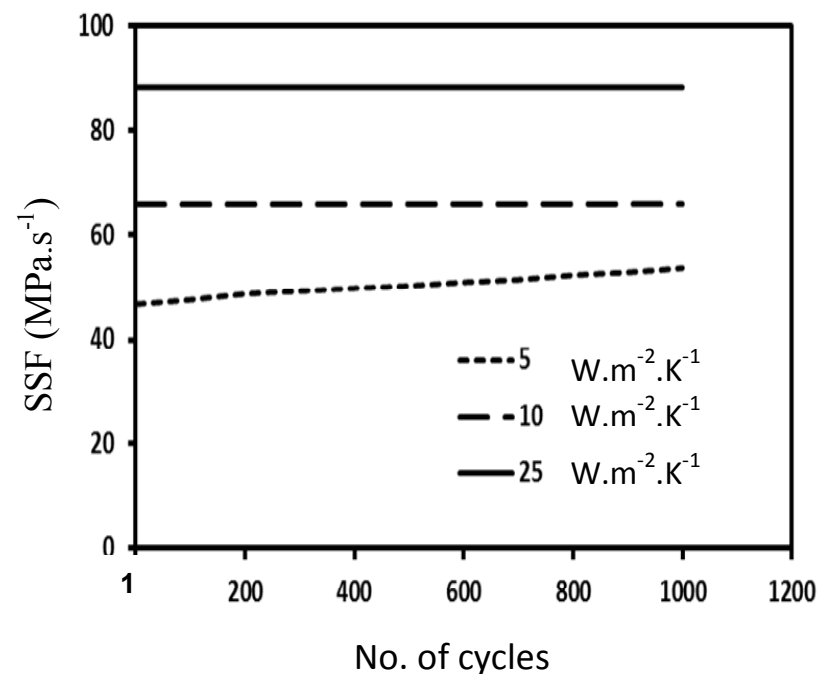

Fig.18. The effect of rapidity of cooling on SSF at 7YSZ/BC interface (point A in Fig.2 ) over 1000 thermal cycles.

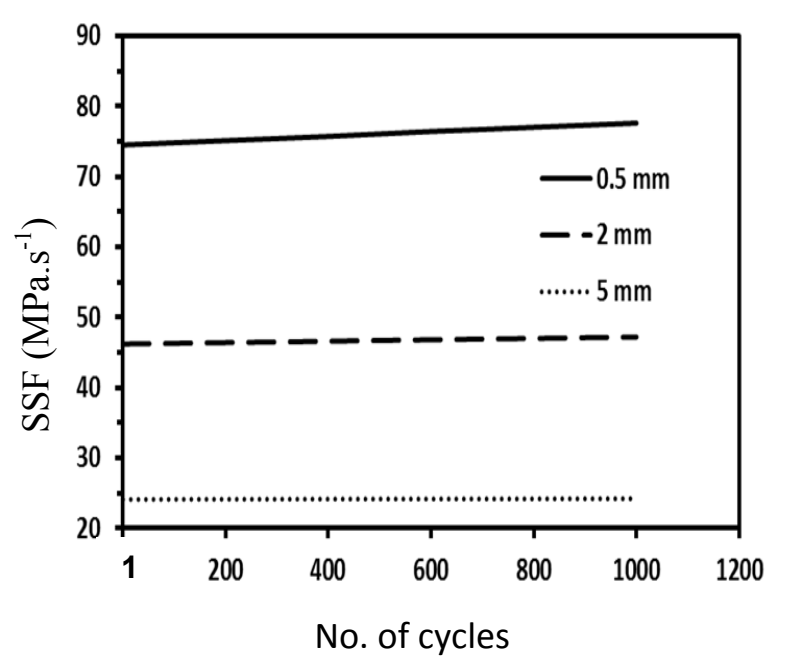

Fig.19. The effect of substrate thickness on SSF at $7 \mathrm{YSZ} / \mathrm{BC}$ interface (Point $\mathrm{A}$ in Fig.2.)

\section{Conclusion remarks}

A two-dimensional coupled-field generalized plane strain finite element simulations have been carried out to evaluate residual stress build-up in a thermal barrier coating during thermal cycling. Parameters which affect the life of thermal barrier coatings, such as the substrate and top coat thickness, cooling rate, dwell and cooling times have been considered for simulating the residual stress build-up during 1000 thermal cycles. Stress severity factors are calculated to quantify the significance of these parameters on residual stress build-up. Out of the three parameters considered in this study, we have observed that the cooling rate, substrate thickness and top coat thickness variations change the stress profile significantly and the stress severity factor increases non-linearly. Overall, the predictions of the model agree with the experimental as well as simulated reported results. The modelling work presented in this study contributed to a better understanding of the effect of residual thermal stress build-up during 1000 thermal cycles. 


\section{Acknowledgements}

We express our earnest thanks to Dr. A.A Gokhale, Director DMRL for his constant encouragement and guidance. The authors would also like to thank DRDO for financial support. This work is carried-out under the project DMR- 294.

\section{Nomenclature}

$C_{p}$ - specific heat capacity

$E$ - elastic modulus of the material

$F_{x}$ - force in $x$ direction

$F_{y}$ - force in $y$ direction

$K$ - strength coefficient

$k$ - thermal conductivity

$n$ - strain hardening exponent

$Q$ - heat source

$T$ - temperature at any instant

$T_{\text {ref }}$ - reference temperature

$\alpha-$ coefficient of thermal expansion

$\varepsilon_{x}$ - strains in $x$ direction

$\varepsilon_{y}$ - strains in $y$ direction

$v$ - Poisson ration

$\rho$ - density

$\sigma$ - stress

$\sigma_{t b}-$ thermal stress

$\sigma_{x}-$ stress in $x$ direction

$\sigma_{y}-$ stress in $y$ direction

$\tau_{\mathrm{xy}}$ - shear stress

\section{References}

Alperine S. and Lelait L. (1994): Microstructural investigations of plasma-sprayed yttria partially stabilizes zirconia TBC. - Transactions ASME - Journal of Engineering for Gas Turbines and Flows, vol.116, pp.258-265.

Bednarz P. (2007): Finite Element Simulation of Stress Evolution in Thermal Barrier Coating Systems. - Ph. D Thesis, Forschungszentrum Jülich.

Bialas M. (2008): Finite element analysis of stress distribution in thermal barrier coatings. - Jl. of Surf. Coat. Tech., vol.202, pp.6002-6010.

Chen Xiao, Zhang Yue and Gong Sheng (2005): Finite element analysis of stresses and interface crack in TBC system. - Trans. Non-Ferrous Met. Soc. China, vol.15, No.2, pp.457-460.

Chun-Hway, Hsnech and Edwin R. Fuller Jr (2000): Residual stresses in thermal barrier coatings: effects of interface asperity curvature/height and oxide thickness - Material Science and Engineering A, vol.283, pp.46-55.

Clarke D.R. and Levi C.G. (2003): Materials design for the next generation thermal barrier coatings. - Annu. Rev. Mater. Res, vol.33, pp.383-417.

Evans A.G., Mumm D.R., Hutchinson J., Meier G.H. and Zettit F.S. (2001): Mechanism controlling the durability of thermal barrier coatings. - Progress in Materials Sci., vol.46, pp.505-553.

Evans A.G., Hutchinson J.W. and Wei Y. (1999): Interface adhesion: effects of plasticity and segregation. - Acta Mater., vol.47, No.15, pp.4093.

Faulhaber S., Mercer C., Moon M.W., Hutchinson J.W. and Evans A.G. (2006): Buckling delamination in compressed multilayers on curved substrates with accompanying ridge cracks. - J. Mech. Phys. Solids, vol.54, pp.1004-1028. 
He M.Y., Evans A.G. and Hutchinson J.W. (2000): The ratcheting of compressed thermally grown oxide on ductile substrate. - Acta Mat., vol.48, pp.2593-2601.

Helminiak M.A. (1998): Factors effecting the lifetime of thermal barrier coatings. - Mech. of Mat., vol.26, pp.91-110.

Hsueh C.H. and Fuller E.R. (2000): Analytical modeling of oxide thickness effects on residual stresses in thermal barrier coatings. - Scripta Materialia, vol.42, pp.781-787.

Hutchinson J.W. (2001): Delamination of compressed multilayers on curved Substrates. - J. Mech. Phys. Solids, vol.49, pp.1847-1864.

Johnson C.A., Ruud J.A. and Bruce R. (1998): Relationships between residual stress, microstructure and mechanical Properties of electron beam-physical vapor deposition thermal barrier coatings. - Surface and Coatings Technology, vol.108, pp.80-85.

Karlsson A.M., Levi C.G. and Evans A.G. (2002): A model study of displacement instabilities during cyclic oxidation. Acta Materilia, vol.50, pp.1263-1273.

Karlsson A.M., XU T. and Evans A.G. (2002): The effect of the thermal barrier coating on the displacement instability in thermal barrier systems. - Acta Materilia, vol.50, pp.1211-1218.

Karlson A.M. and Evans A.G. (2001): A numerical model for the cyclic instability of thermally grown oxides in thermal barrier systems. - Acta Mater., vol.49, pp.1793-1804.

Lee J.D., Ra H.Y., Hong K.T. and Hur S.K. (1992): Analysis of deposition phenomena and residual stress in plasma spray coatings. - Surf. Coat. Tech., vol.56, No.1, pp.27-37.

Limarga A.M., Widjaja, Sujanto, Yip, Tick Hon, Teh, Lay Kuan (2002): Modeling of the effect of $\mathrm{Al}_{2} \mathrm{O}_{3}$ interlayer on residual stress due to oxide scale in thermal barrier coatings. - Surface and Coatings Technology, vol.153, No.1, pp.16-24.

Mao W.G., Jiang J.P., Zhou Y.C. and Lu C. (2011): Effects of substrate curvature and radius, deposition temperature and coating thickness on the residual stress field of cylindrical thermal barrier coatings. - Surface and Coatings Technology, vol.8-9, pp.205-211.

Mao W.G. and Y. Zhou Y.C. (2005): Failure of thermal barrier ceramic coating induced by buckling due to temperature gradient and creep. - Advanced Mat. Res., vol.9, pp.31-40.

McGrann R.T., Greving D.J., Shadley J.R., Rybicki E.F., Kruecke T.L. and Bodger B.E. (1998): The effect of coating residual stress on the fatigue life of thermal spray-coated steel and aluminum. - Surf. Coat. Tech., vol.108, pp.5964.

Meier S.M. and Gupta D.K. (1994): The evolution of thermal barrier coatings in gas turbine engine applications. Trans. ASME, vol.116, pp.250-256.

Miller R.A. (1997): Thermal barrier coatings for aircraft engines: history and directions. - J. Therm. Spray Technology, vol.6, pp.35-42.

Pan D., Chen M.W., Wright P.K. and Hemker K.J. (2003): Evolution of a diffusion aluminide bond coat for thermal barier coatings during thermal cycling. - Acta Mat., vol.51, pp.2205-2217.

Pekshev P.Y. and Murzin I.G. (1993): Modeling of porosity of thermal barrier coatings. Surf. Coat. Tech., vol.56, pp.199-208.

Qian G., Nakamura T. and Berndt C.C. (1998): Effects of thermal gradient and residual stresses on thermal barrier coating. - Mechanics of Materials, vol.27, pp.91-110.

Scardi P., Leoni M., Bertamini L. and Marchese M. (1996): Residual stress in coatings on piston heads. - Surf. Coat. Tech., vol.86, pp.109-115.

Schwingel D., Taylor R., Haubold T., Wigren J. and Gualco C. (1998): Mechanical and thermo-physical properties of thick YSZ, thermal barrier coatings: correlation with microstructure and spraying parameters. - Surf., Coat., Technol., vol.108, pp.99-106.

Shillington E. and Clarke D.R. (1999): Spalling failure of a thermal barrier coating associated with aluminium depletion in the bond coat. - Acta Mat., vol.47, pp.1297-1305. 
Srivathsa B., Zafir Alam Md, Kamat S.V. and Das D.K. (2011): Modelling of residual stresses developed in thermal barrier coatings during thermal cycling. - Int. J. App. Mechanics and Engg., vol.16, No.3, pp.869-883.

Stephan S (1985): Advanced thermal barrier system coatings for use on Ni-,co-, and Fe-based substrates. - Lewis Research Center: No.NASA-TM-87062, Cleveland, Ohio.

Sujanto Widjaja, Andi Limarga and Tick Hon Yip (2003): Modelling of residual stresses in a thermally graded thermal barrier coating. - Thin Solid Films, vol.434, pp.216-227.

Teixeira V., Andritschky M. and Fischer W. (1992): Analysis of residual stresses in thermal barrier coatings. - J. of Mat. Pro. Technology, vol.92, pp.209-216.

Wright P.K. and Evans A.G. (1999): Mechanisms governing the performance of TBCs. - Current opinions in Solid State and Mater. Sci., vol.4, pp.255-65.

Zhang Yue, Zhang Yarji, Jinghua Gu (2001): A computational simulation of interaction between polyelectrolyte and ceramic particles. - Key Engg. Materials, vol.224, pp.697-701.

Zhu D.M. and Robert A.M. (1999): Determination of creep behaviour of thermal barrier coatings under laser imposed high thermal and stress gradient conditions. - J. Mater. Res., vol.14, pp.146-161.

Received: June 11, 2014

Revised: October 1, 2015 